\title{
Cost-effective and scalable architecture for moving cell application employing integrable tunable laser assembly
}

\section{Citation for published version (APA):}

Tran, N. C., Okonkwo, C., Tangdiongga, E., \& Koonen, T. (2012). Cost-effective and scalable architecture for moving cell application employing integrable tunable laser assembly. In Proceedings of the Optical Fiber Communication Conference and Exposition (OFC/NFOEC), 2012 and the National Fiber Optic Engineers Conference, 4-8 march 2012, Los Angeles, California (pp. OTu2H.7). [6192077] Institute of Electrical and Electronics Engineers.

Document status and date:

Published: 24/05/2012

\section{Document Version:}

Publisher's PDF, also known as Version of Record (includes final page, issue and volume numbers)

\section{Please check the document version of this publication:}

- A submitted manuscript is the version of the article upon submission and before peer-review. There can be important differences between the submitted version and the official published version of record. People interested in the research are advised to contact the author for the final version of the publication, or visit the $\mathrm{DOI}$ to the publisher's website.

- The final author version and the galley proof are versions of the publication after peer review.

- The final published version features the final layout of the paper including the volume, issue and page numbers.

Link to publication

\section{General rights}

Copyright and moral rights for the publications made accessible in the public portal are retained by the authors and/or other copyright owners and it is a condition of accessing publications that users recognise and abide by the legal requirements associated with these rights.

- Users may download and print one copy of any publication from the public portal for the purpose of private study or research.

- You may not further distribute the material or use it for any profit-making activity or commercial gain

- You may freely distribute the URL identifying the publication in the public portal.

If the publication is distributed under the terms of Article 25fa of the Dutch Copyright Act, indicated by the "Taverne" license above, please follow below link for the End User Agreement:

www.tue.nl/taverne

Take down policy

If you believe that this document breaches copyright please contact us at:

openaccess@tue.nl

providing details and we will investigate your claim. 


\title{
Cost-effective and Scalable Architecture for Moving Cell Application Employing Integrable Tunable Laser Assembly
}

\author{
Nguyen-Cac Tran, Chigo Okonkwo, Eduward Tangdiongga, and Ton Koonen \\ COBRA Research Institute, Eindhoven University of Technology, P.O. Box 513, Eindhoven, 5612 AZ, The Netherlands, \\ Email: c.tran.nguyen@tue.nl
}

\begin{abstract}
We propose a cost-effective, scalable architecture to provide high-speed connection to trains by moving-cells employing tunable lasers in the $\mathrm{CO}$ and passive add/drop multiplexers in the field. The architecture is demonstrated with bidirectional OFDM signals.

OCIS codes: (060.4510) Optical communications; (060.5625) Radio Frequency photonics; (060.4250) Networks
\end{abstract}

\section{Introduction}

The rapid adoption of smart phones and tablets has created unprecedented challenges to mobile service providers. People surfing websites or watching online clips on their handheld devices is becoming common in any public place, especially on trains. To facilitate such scenarios, the moving cell concept has been proposed to provide highspeed and reliable Internet connections for fast-moving passengers [1-3]. Instead of the train frequently crossing radio cells along the railroad, a radio cell is designed to follow the train. Hence, mobile users are able to stay in the same radio cell when traveling to avoid most of cumbersome handovers and packet loss. Mobile users can connect to the cell directly or through a radio head-end installed in the train.

Fiber-optic infrastructures together with radio over fiber techniques have been investigated to implement the moving cell concept. The radio base station is located in the central office (CO) and radio (RF) signals are transmitted through the fiber to reach a particular remote antenna unit (RAU) where the train is passing by. When the train enters the coverage area of the next RAU, RF signals must be redirected to the appropriate RAU. Currently, an optical switch is employed to route the wavelength, thus RF signals, to the desired RAU [1,3]. The optical switching fabric has to scale up with the number of RAUs leading to a higher system cost. The large optical switching fabric may also degrade the RF signals signal-to-noise ratio (SNR). Furthermore, the use of a laser in RAUs requires a signaling channel between $\mathrm{CO}$ and RAUs to activate and deactivate RAUs with strict timing to avoid interference.

In this paper, we propose a new architecture employing tunable lasers, fixed optical add/drop multiplexers (OADM), and remotely-fed RAUs. A tunable laser tunes the wavelength to address a particular RAU to avoid using an optical switch. Two relatively-slow tunable lasers are used in an alternating scheme instead of using an expensive fast tunable laser. Fixed OADMs coded by their add/drop lambda index to add/drop the pre-assigned wavelengths to RAUs. For the uplink, the RAU using an external modulator to modulate remotely-fed continuous wave signals to avoid using any laser source in the RAU.

\section{Moving Cell Architecture Employed ITLA}

Figure 1 depicts the schematic representation of the proposed architecture. There are two pairs of integrable tunable laser assemblies (ITLAs) which are specified by optical internetworking forum (OIF) [4]. The ITLA is selected because it is a standardized device for WDM networks that has the advantage of market volume, leading to lower cost. The first pair (ITLA1 and ITLA $1 *$ ) is employed for downstream transmission. When an ITLA is tuned to an RAU that cover the passing train, the other ITLA is disabled and pre-tuned to the next RAU wavelength. When the train enters the coverage area of the next RAU, the pre-tuned ITLA is enabled and the active ITLA is disabled and prepared for the next round. By this scheme, we can control switching time from one RAU to the next by overlapping the switch-on time of the pre-tuned ITLA and switch-off time of the active ITLA. The wavelength from

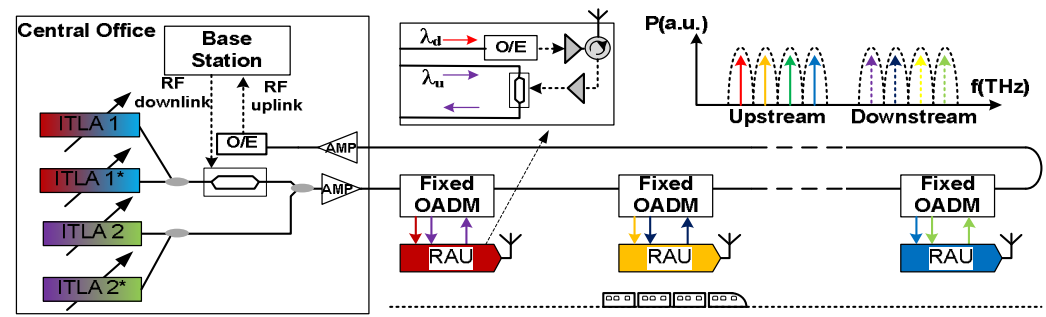

Fig. 1. Reconfigurable optical network architecture for moving cells by employing integrable tunable laser assemblies and fixed optical add/drop multiplexers, and remotely-fed RAUs 


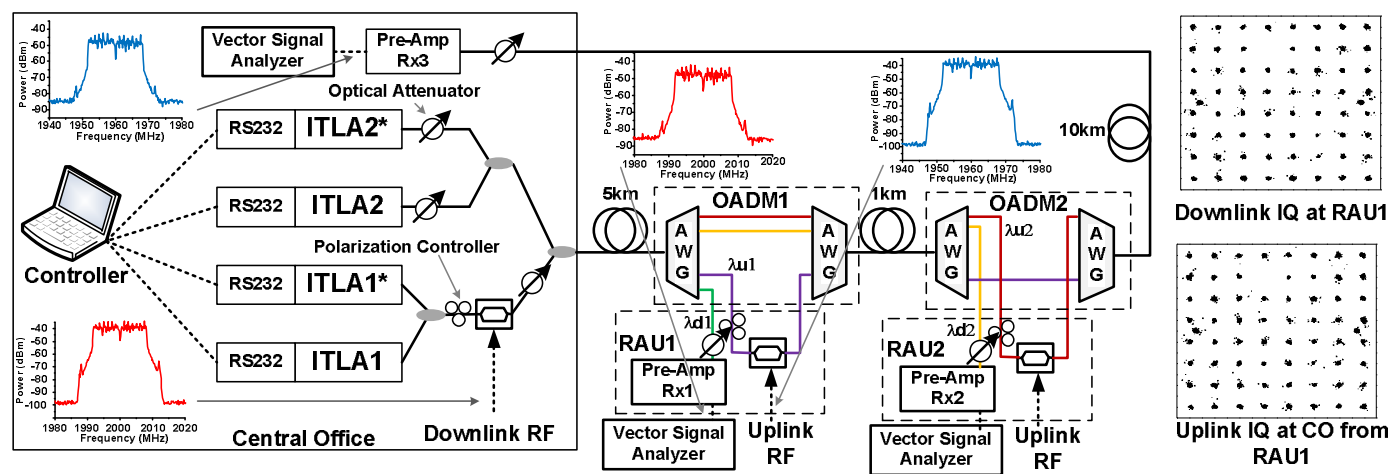

Fig. 2. Experimental setup with two OADMs associated with two RAUs and four pc-controlled ITLAs at the central office

the downstream ITLA pair is modulated by RF downlink signals using an intensity modulator. The modulated wavelength is then combined with a $\mathrm{CW}$ wavelength generated by the second pair of ITLA (ITLA2, ITLA2*) for remote modulation at the RAU. The second pair of ITLA operates also in the alternating scheme similar to the first pair. The modulated and CW wavelength are launched to the optical distribution network (ODN) and dropped by the destined OADM. The CW wavelength is modulated by the uplink RF signal by an intensity modulator and added back to the ODN. There are two options for the upstream wavelength returning to the CO. In the refection choice, the upstream wavelength can reflect back to the same path by which it reaches the RAU. However, the signal is exposed to reflections from the $\mathrm{CW}$ transmission e.g., Rayleigh backscattering, and reflections inside to OADMs. Furthermore, the wavelength from different RAUs travels through different path length and number of OADMs leading to a fluctuation in received optical power. Therefore, we adopt the move-forward option in which the upstream wavelength continues transmitting through the rest of OADMs and return to the $\mathrm{CO}$ via another fiber path after the last OADM. This method avoids the reflection from CWs transmission and also the fluctuation of received power of the upstream wavelength. From the point that the CW launched to the ODN and the point that the upstream wavelength received at the $\mathrm{CO}$, the upstream wavelength of any RAU experiences similar loss (gain if amplifiers used in the field) to the other since they travel through the same path length and all OADMs.

One of the advantages of having remotely-fed RAU is that the RAU can be activated and deactivated by controlling the lasers in the $\mathrm{CO}$ without any further action in the RAU. If the RAU uses a local laser for upstream transmission, the $\mathrm{CO}$ has to signal the RAU to switch the laser off on time in order to avoid interference. The train tracking algorithm is used to activate the right RAU at the right time by controlling only ITLA array at the CO. If the base station allows multiple-input-multiple-output (MIMO) operation, two or more consecutive RAUs can be activated simultaneously as called moving chain cells in [3]. To realize such scheme, we need to install more ITLAs at the $\mathrm{CO}$ with the number determined by the number of simultaneously active RAUs.

\section{Experimental Results and Discussions}

The proof of concept experiment setup is shown in Fig. 2 in which an array of ITLAs controlled from a computer. The downstream wavelength is modulated by the downlink OFDM (orthogonal frequency division multiplexing) signal centered at $2 \mathrm{GHz}$ using a 10-GHz LN intensity modulator. The OFDM signal has 53 subcarriers in which the subcarrier indices - 26 and 26 are two pilot carriers using BPSK (binary phase shift keying) and the other subcarriers except zero carry 54 Mbps pseudo random bit sequence of $2^{-23}-1$ (PRBS-23) using 64-QAM. The downstream and the upstream $\mathrm{CW}$ wavelength reach the first OADM after traveling through 5-km standard SMF fiber. The OADM, constructed by two C-band 16-channel 200-GHz-spaced array waveguide gratings (AWGs), drop $\lambda \mathrm{d}_{1}(1562.23 \mathrm{~nm}$ ) and $\lambda \mathrm{u}_{1}(1549.32 \mathrm{~nm})$. The $\mathrm{CW} \lambda \mathrm{u}_{1}$ is modulated by the uplink OFDM signal, formatted similar to the downlink, centered at $1.96 \mathrm{GHz}$ using another $10-\mathrm{GHz} \mathrm{LN}$ intensity modulator. After modulation, $\lambda \mathrm{u}_{1}$ is added back to the ODN and travel through the second OADM to return to the CO. If the RAU2 is activated, $\lambda \mathrm{d}_{2}(1560.61 \mathrm{~nm})$ and $\lambda \mathrm{u}_{2}$ $(1547.72 \mathrm{~nm})$ pass through the first OADM to be dropped by the second OADM. The $\lambda \mathrm{u}_{2}$ is modulated by the uplink signal and added back to the ODN to return to the CO.

The experiment uses Oclaro TL5000DCJ ITLA, which can cover 88 wavelengths from $1529.16 \mathrm{~nm}$ (channel 88) to $1563.86 \mathrm{~nm}$ (channel 1) in 50-GHz grid. The ITLA wavelength switching characteristic is shown in Fig. 3a where the laser is tuned from channel 88 to channel 1 composed of three phases. The laser completely switches off in $92 \mathrm{~ns}$ in the first phase and then it enters a dark tuning period of $2.944 \mathrm{~ms}$ in the second phase. In the last phase, the laser switches on the new wavelength in $1.516 \mathrm{~ms}$. The switching time is tested over a large number of combinations of source and destination wavelength in which the negligible variation in switching time is observed. As described in the previous section, one laser in a pair of ITLAs is disabled, pre-tuned to the next RAU, and enabled when the RF 

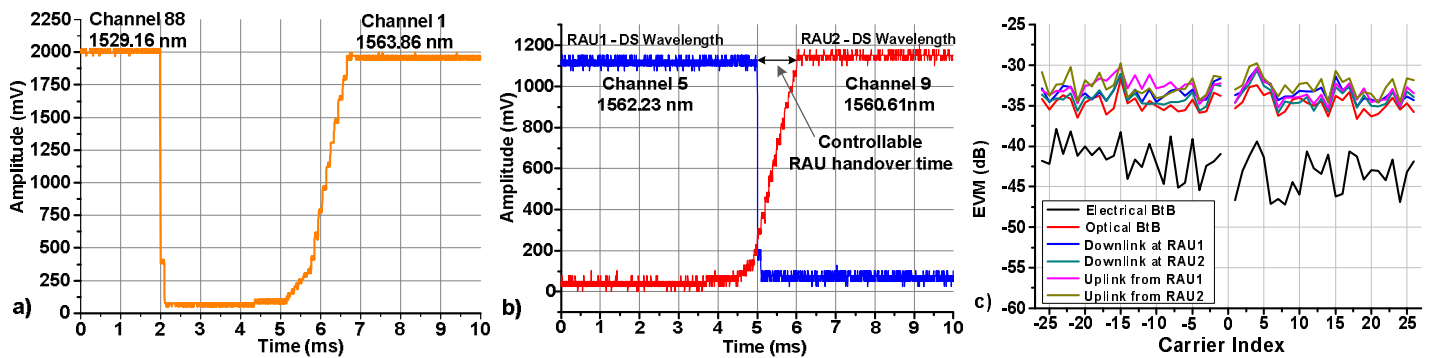

Fig. 3. a) Oclaro TL5000DCJ ITLA wavelength switching time, b) Controllable RAU handover time by overlaping ITLA wavelength switching time, c) Average EVM vs. subcarrier index in various mesurement cases

signal is handed to that RAU. However, the TL5000DCJ laser enabling time is $100 \mathrm{~ms}$, which is much longer than the wavelength switching time. Therefore, we adopted a solution in which the laser is virtually disabled by tuning to an unused wavelength to exploit the short laser switch-on phase of $1.516 \mathrm{~ms}$. In that state, the output of the laser cannot be detected in any RAU. Fig. 3b shows the time trace of downstream wavelengths at RAU1 and RAU2 during the handover period. In time $\mathrm{t}_{0}$, ITLA1 is programmed to switch from channel $5\left(\lambda d_{1}\right)$ to channel 88 (the virtually disabled wavelength) to disable RAU1. In time $\mathrm{t}_{\mathrm{S}}\left(3.5 \mathrm{~ms}\right.$ before $\left.\mathrm{t}_{0}\right)$, the ITLA $1 *$ was programmed to switch from channel 88 to channel $9\left(\lambda d_{2}\right)$. In this case, we observe the RAU handover time of $1 \mathrm{~ms}$. The handover time can be controlled by the offset between $\mathrm{t}_{\mathrm{s}}$ and $\mathrm{t}_{0}$ to yield the optimal value.

To evaluate the impairment introduced by the optical path to RF signals, the error vector magnitude (EVM) of each subcarrier excluding the handover period is measured and shown in Fig. 3c. The electrical back-to-back case has the lowest EVM while the results from the optical cases are closer in performance. Among the optical cases, the lowest curve is the optical back-to-back which shows $7.8 \mathrm{~dB}$ average penalty in comparison to the electrical back-toback. Since the other optical cases are very close to the optical back-to-back, we conclude that the optical modulation and detection of RF signals are the dominant impairment source not the transmission through the system. In all transmission cases, the average EVM performance of all carriers is around $-34 \mathrm{~dB}(2.2 \%)$ providing adequate margin for air transmission within the standards.

To scale up the system with a number of OADMs, the dominant constraint is the optical budget since each OADM introduces a certain insertion loss to the express channels. For instance, the OADM in the experiment introduces $3.5 \mathrm{~dB}$ insertion loss. A careful design of dual OADM can reduce the insertion loss to $1.4 \mathrm{~dB}$ as shown in [5] which is still substantial. To increase the optical budget, we can use optical amplifiers in the ODN or parallelize the system. An AWG can be used at the CO instead of cascading OADMs to route wavelengths to RAUs. However, much more fibers should be deployed in the field, which may not desirable. A band splitter at the CO and OADMs in the field can realize a compromise solution between parallel and serial. The band splitter splits the bandwidth to several sub-bands and each sub-band is conducted by one fiber to a serial of OADMs, which is a subset of all OADMs in the system. Optical channel crosstalk by cascading OADMs is another constraint but not dominant since only the wavelengths, which address the same RAU, are present at one time. These wavelengths can be selected to have a large spectral distance to further mitigate crosstalk.

\section{Conclusion}

In this paper, we proposed a new architecture for moving cell application. The RAU can be activated and deactivated by controlling the optical sources at the $\mathrm{CO}$ without any further operations at the RAU. A pair of standardized and mass-produced tunable lasers was employed not only because of cost but also to yield controllable RAU handover time. The proposed system was demonstrated by transmitting downlink and uplink OFDM signal with 53 subcarriers carrying $54 \mathrm{Mb} / \mathrm{s}$ data. The EVM performance of downlink and uplink signal from both RAUs was $-34 \mathrm{~dB}(2.2 \%)$. We further discussed the system scalability where we argued that power budget is the dominant constraint. To overcome the constraint, we suggested using amplifiers in the field to increase the power budget or parallelize the system to reduce the number of cascaded OADMs, thus the power budget requirement.

\section{References}

[1] B. Lannoo, et al., "Radio-over-Fiber-Based Solution to Provide Broadband Internet Access to Train Passengers," Commun. Mag., pp. 56-62 (2007).

[2] C.H. Yeh, et al., "Theory and Technology for Standard WiMAX Over Fiber in High Speed Train Systems," J. Lightw. Tech., vol. 28, no. 16, pp. 2327-2336 (2007).

[3] Y.T. Hsueh, et al., "A Novel Wireless over Fiber Access Architecture Employing Moving Chain Cells and RoF Technique for Broadband Wireless Applications on the Train Environment," OFC/NFOEC, p. OWT3 (2011).

[4] Optical Internetworking Forum OIF, "Integratable Tunable Laser Assembly Multi Source Agreement," (2004)

[5] AC Photonics, "100GHz Dual Channel OADM," Available: http://www.acphotonics.com (2011). 